\title{
Role of Pressure Therapy in the Management of Earlobe Clefts
}

\author{
${ }^{1}$ Neha Sikka, ${ }^{2}$ Shashi Bala, ${ }^{3}$ Meenu Dhiman, ${ }^{4}$ Rachit Khatana, ${ }^{5}$ Balram Garg
}

\begin{abstract}
Congenital cleft of earlobe is a rare malformation showing a wide range of severity. The surgical closure of the cleft is an indispensable treatment modality but the treatment should be customized according to the situation. The postsurgical cosmetic results are not always satisfactory as they are dependent on the location and amount of deficient tissues. Predictable esthetic results can be achieved by adopting comprehensive treatment protocol including a staged surgery and pressure therapy. The case report describes the provision of pressure therapy with an esthetically pleasing, inexpensive, custommade ear pressure clip for a patient with recently operated congenital cleft earlobe.
\end{abstract}

Keywords: Ear pressure appliance, Earlobe clefts, Pressure therapy.

How to cite this article: Sikka N, Bala S, Dhiman M, Khatana R, Garg B. Role of Pressure Therapy in the Management of Earlobe Clefts. J Oral Health Comm Dent 2017;11(2):48-50.

\section{Source of support: Nil}

Conflict of interest: None

\section{INTRODUCTION}

Pressure therapy using clips, splints, or stents is extensively used in the management of hypertrophic scars and keloids. ${ }^{1-3}$ It is a kind of conservative and minimally invasive treatment that involves the use of prefabricated or custom-made clips, buttons, and earrings. ${ }^{1-3}$ Pressure therapy along with intralesional steroid therapy may be

\footnotetext{
1,3,5 Demonstrator, ${ }^{2}$ Senior Professor, ${ }^{4}$ Postgraduate Student

${ }^{1}$ Department of Prosthodontics, Postgraduate Institute of Dental Sciences, Rohtak, Haryana, India

${ }^{2}$ Department of Dental Materials, Postgraduate Institute of Dental Sciences, Rohtak, Haryana, India

${ }^{3}$ Department of Conservative Dentistry, Postgraduate Institute of Dental Sciences, Rohtak, Haryana, India

${ }^{4}$ Department of Conservative Dentistry, SGT Dental College Hospital \& Research Institute, Gurugram, Haryana, India

${ }^{5}$ Department of Oral Surgery, Postgraduate Institute of Dental Sciences, Rohtak, Haryana, India

Corresponding Author: Neha Sikka, Demonstrator, Department of Prosthodontics, Postgraduate Institute of Dental Sciences Rohtak, Haryana, India, Phone: +919416330633, e-mail: neha. nehasikka@gmail.com
}

used as a conservative nonsurgical treatment approach for the management of auricular keloids and to prevent recurrence. ${ }^{4}$ Pressure therapy alone or as an adjuvant to surgery has shown good results in the management of auricular keloids. ${ }^{1-4}$ Pressure therapy is used in presurgical stage (for reduction in size of lesion) and postsurgical stage (to prevent recurrence by softening the scar tissue) ${ }^{1-4}$ Earlobe clefts can be either acquired or congenital. ${ }^{5}$ Acquired clefts or splitting of earlobe can be afflicted by the wearing of heavy earrings for a prolonged duration or by sudden traumatic injuries like sudden pulling of earring by a child or a snatcher. ${ }^{5}$ Congenital earlobe clefts or Coloboma lobuli is a very rare congenital auricular deformity, which is a result of failure of fusion between tragus and lobule. ${ }^{5}$ Cleft earlobes have been classified variously by different authors. Yamada et $\mathrm{al}^{6}$ classified ear clefts as anterior, posterior, and double-lobe types, whereas these were classified as simple and hypoplastic by Matsumoto. ${ }^{7}$ On the contrary, four subtypes of earlobe clefts (longitudinal, transverse, triple lobe, and defective) were described by Kitayama et al. ${ }^{8}$ The surgical repair of the defect is a viable treatment option. Pressure therapy in addition to the surgical repair is expected to show better esthetic results. The case report describes the management of a patient with congenital longitudinal cleft of earlobe.

\section{CASE REPORT}

A 20-year-old female patient reported to the Department of Prosthodontics, from the Department of Plastic Surgery for the fabrication of ear pressure appliance. The patient gave a history of a cleft earlobe on the left side since childhood (Fig. 1) and she was operated for this condition 7 days back (Fig. 2). The patient provided no relevant family history. The patient did not get any treatment previously for the condition. For cosmetic reasons the patient decided to get the condition treated. The treatment of the patient was planned in stages. In stage I (surgical), a lateral displacement flap procedure was undertaken for correction of the cleft. This was followed by a healing phase. In stage II (prosthetic), pressure therapy was given using a custom-made polymethylmethacrylate ear pressure clip. In stage III, a revision surgery was done to provide best possible cosmetic results. 


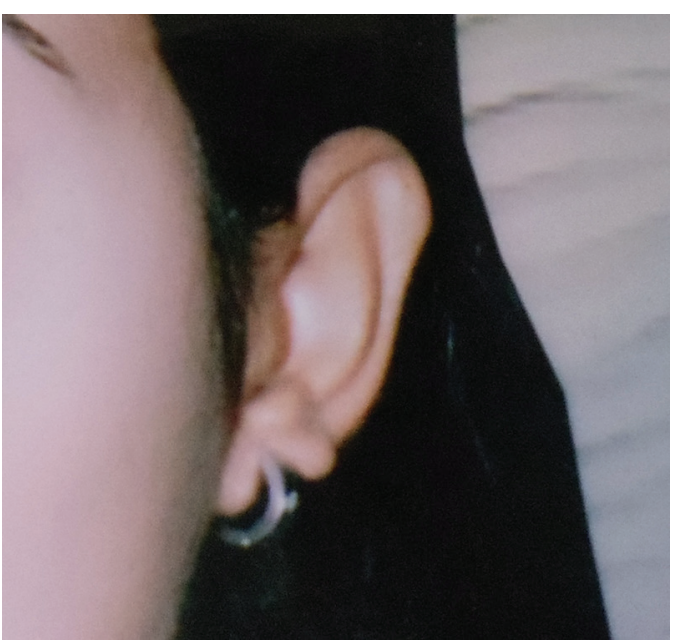

Fig. 1: Presurgical view of patients ear showing cleft earlobe

\section{FABRICATION OF EAR PRESSURE CLIP}

The lubrication of the pinna of the left side and the adjacent area up to the hair line with petroleum jelly was done. A boundary using impression compound was made for confinement of the impression material. Impression was made in light body addition silicone (3M ESPE Express, VPS Impression Material, USA) and was reinforced with addition silicone having putty consistency to prevent distortion (Fig. 3). The beading of the impression was done and poured to fabricate the working cast. A V-shaped $19 \mathrm{G}$ stainless steel wire spring was fabricated with a coil in center. Space between the wire coil and the tissues was maintained to prevent impingement and to provide space for acrylic resin. The outer acrylic pad was tinted with acrylic colors to simulate the skin color of the patient (to make the appliance esthetically acceptable). The appliance was finished and polished and placed over the desired area (Fig. 4). The patient was advised to wear the appliance 24 hours a day for 1 month. A follow-up appointment was scheduled after 2 days of insertion to check for any signs of impingement. This was followed by the second (revision) surgery.

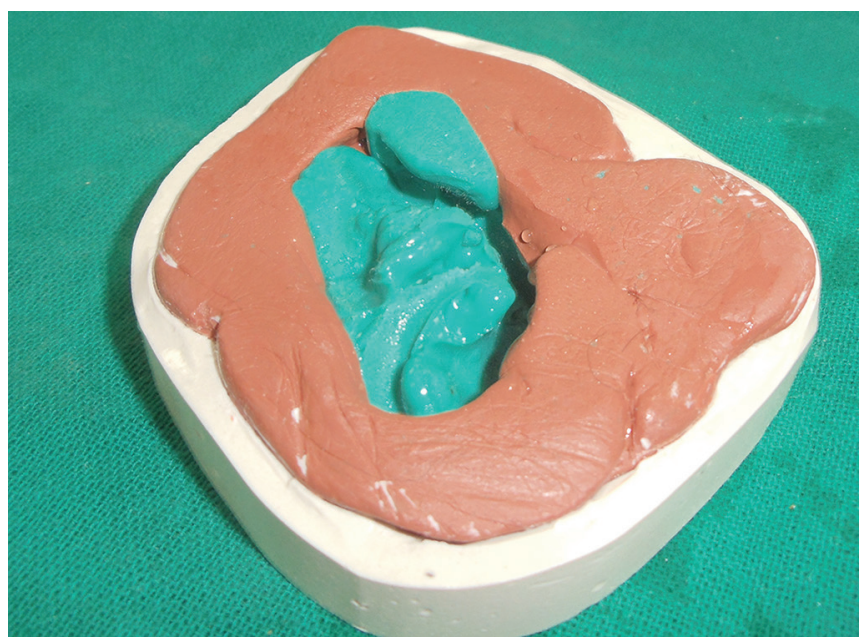

Fig. 3: Impression of the patients ear made in addition silicone

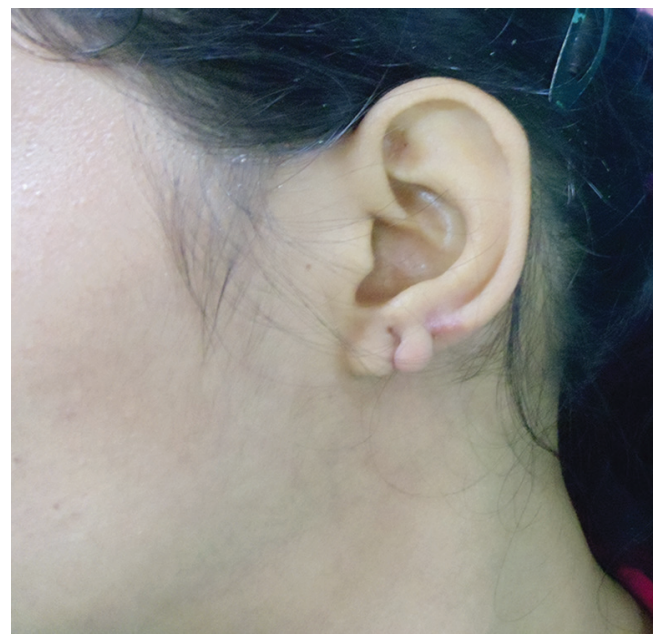

Fig. 2: Photograph of patient taken after stage I surgical procedure

\section{DISCUSSION}

The well-formed and symmetrically positioned ears are considered as a sign of esthetics and any deformities in this region are very obvious. ${ }^{5}$ The clefts may be present unilaterally or bilaterally. ${ }^{5}$ Usually the patients with cleft earlobe require surgical repairs. $5,7,9,10$ The surgery can be carried out at any age but it is wise to wait till the time the patient becomes sensible and cooperative. Various surgical techniques can be employed for the correction of earlobe clefts like Z-plasty, L-plasty two-flap method, triangular flap method, and so on, depending on the factors like location of cleft (horizontal, vertical, or oblique) and the amount of tissue present (adequate or inadequate). 5,7,9,10 The surgical repair aims to restore the natural esthetics of the earlobe with minimal tissue sacrifice. ${ }^{5}$ Most of the female patients aspire to wear earrings after the surgery but most of the surgical procedures do not allow repiercing. ${ }^{5}$ The surgical technique needs to be customized according to the specific defect. ${ }^{5,7,9,10}$ The donor-site scars and unusual shape or size of the reconstructed lobule are certain undesirable cosmetic results. ${ }^{5,10}$ Such disasters in treatment

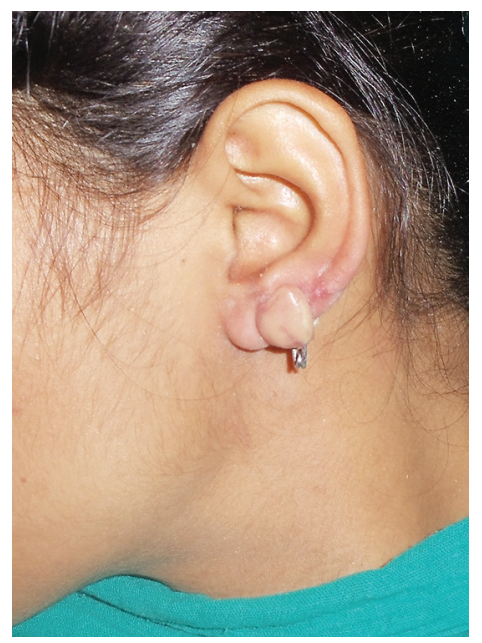

Fig. 4: Characterized fabricated ear pressure clip 
can be avoided by staged surgical procedures and the use of pressure therapy. ${ }^{5,10}$ Numerous devices like ear pressure clips, cling on earrings, buttons, or silicon pressure packing can be used to provide pressure therapy. ${ }^{1-4}$ The custom-made appliances are preferable attributing to the complex anatomy of the pinna, which interferes with the alignment of the appliance and the provision of adequate pressure. ${ }^{1-4}$ The mechanism of action of the pressure appliance is still unclear. The hypoxic environment created by the application of pressure $(24-30 \mathrm{~mm} \mathrm{Hg}$ ) which exceeds the capillary pressure leading to fibroblastic degradation may be an apt explanation of the mechanism of action of pressure appliance. ${ }^{2}$ The application of sufficient, continuous, and controlled pressure is a basic requirement of pressure therapy. ${ }^{1-4}$ The appliance in the present case was designed to exert controlled and continuous pressure over the desired area. The appliance is esthetic, inexpensive, easy to use, and easily adjustable. The usage of this appliance is dependent on the patient compliance. For a successful outcome with the pressure therapy, patient motivation plays an important role. The importance of wearing the appliance for a sufficient amount of time should be emphasized and explained to the patient for best outcomes.

\section{CONCLUSION}

A simple, esthetic, and inexpensive appliance has been described for the application of continuous and controlled pressure on the immature surgical wound for modulation of the wound healing process and to produce best possible results.

\section{REFERENCES}

1. Hurtado AJ, Crowther DS. Methyl methacrylate stent for prevention of postexcisional recurrent ear keloid. J Prosthet Dent 1985 Aug;54(2):245-250.

2. Chrisostomidis C, Konofaos P, Chrisostomidis G, Vasilopoulou A, Dimitroulis D, Frangoulis M, Papadopoulos O. Management of external ear keloids using form-pressure therapy. Clin Exp Dermatol 2008 May;33(3):273-275.

3. Sela M, Taicher S. Prosthetic treatment of earlobe keloids. J Prosthet Dent 1984 Sep;52(3):417-418.

4. Agrawal K, Panda KN, Arumugam A. An inexpensive self fabricated pressure clip for the ear lobe. Br J Plast Surg 1998 Mar;51(2):122-123.

5. Niamtu J. Surgical repair of the cleft earlobe. J Oral Maxillofac Surg 1997 Aug;55(8):886-890.

6. Yamada A, Fukuda O, Soeda S. The evaluation of cleft earlobe. Jpn J Plast Reconstr Surg 1976;19:171.

7. Matsumoto K. Surgical repair of the congenital ear lobe cleft. Br J Plast Surg 1981 Oct;34(4):410-413.

8. Kitayama Y, Yamamoto M, Tsukada S. Classification of congenital cleft earlobe. Jpn J Plast Reconstr Surg 1980 Jan;23: 663-670.

9. Bhandari PS. Congenital cleft earlobe: surgical repair. Plast Reconstr Surg 2001 Sep;108(4):986-987.

10. Conard K, Reifen E. Congenital cleft earlobe deformity: a staged reconstruction. J Otolaryngol 1994 Feb;23(1):19-22. 